\title{
ENVIRONMENTALLY PERSISTANT TOXICANT ARSENIC AFFECTS UTERUS GROSSLY AND HISTOLOGICALLY
}

\author{
M. A. Wares*, M. A. Awal, S. K. Das and J. Alam \\ Department of Anatomy and Histology, Faculty of Veterinary Science, Bangladesh Agricultural University, \\ Mymensingh-2202, Bangladesh
}

\begin{abstract}
The experiment was carried out to determine the gross and microscopic effects of arsenic on uterus of female Black Bengal Goats against control group in the Department of Anatomy and Histology, Faculty of Veterinary Science, Bangladesh Agricultural University, Mymensingh-2202. A total of twelve mature female Black Bengal goats were studied, six from arsenic affected areas of Mymensingh district and theother six from Hill Tracts of Bangaldesh which are arsenic free. Gross parameters show slight variations in the morphology (color and shape) and biometry (size and weight) of uterus of arsenic affected Black Bengal goats, but this variation was statistically insignificant $(p>0.05)$. For microscopic study, permanent slide was prepared by Mayer's Hematoxylin and Eosin stain method. In microscopic level, there were significant variations in arsenic affected group of goats compared to the control group. Arsenic affected group of goats show thickening of uterine horn $(p<0.01)$, uterine gland is lower in amount and diameter $(p<0.01)$, cervical villi length was smaller $(p<0.01)$, cervical wall thickness was higher $(p<0.01)$. This work may be the tip of the iceberg representing the full extent of arsenic exposure to female genital tract.
\end{abstract}

Key words: Goat, Reproductive tract, Arsenic, Effects

\section{INTRODUCTION}

Goat is the earliest domesticated ruminant (Zeuner, 1963) is found across all agro-ecological environments. Presently, goat (677 millions) is the fourth largest livestock in the world (Morand-Fehr et al., 1999). The goat ranks second in terms of meat, milk and skin production representing about 28, 23 and 28 percent among the total contribution of livestock respectively, in Bangladesh (FAO, 1997). Black Bengal goat is more important for their kidding capacity. They get puberty in 6-7 months and its gestation period is only $150 \pm 5$ days. The livestock sub-sector plays vital role for the economic development of agro-based Bangladesh.

Arsenic (As) is a xenobiotic metalloid with symbol As and ubiquitously distributed in nature. Arsenic and its compounds are best known as a deadly poison (ATSDR, 2005). Arsenic displays different valences $(-3,0,+3,+5)$ resulting in a broad variety of arsenic compounds with diverse physical and chemical properties. It ranked first in a list of 20 hazardous substances by the Agency for Toxic Substances and Disease Registry (ATSDR) and United States Environmental Protection Agency (US EPA) (Goering et al., 1999). Though arsenic is an extremely poisonous substance, it has numerous industrial applications. The poison was molded into a medicine in the year 1780, when English inventor Thomas Fowler developed 1\% solution of potassium arsenite $\left(\mathrm{K}_{3} \mathrm{AsO}_{3}\right)$ for the treatment of asthma, chorea, eczema, pemphigus and psoriasis. Donovan's solution, arsenic triiodide $\left(\mathrm{AsI}_{3}\right)$ and De Valagin's solution, arsenic trichloride $\left(\mathrm{AsCl}_{3}\right)$ were recommended to treat rheumatism, arthritis, malaria, trypanosome infections, tuberculosis and diabetes. Before invention of penicillin, it was used empirically for the treatment of a variety of diseases including leprosy, syphilis and yaws. $\mathrm{As}_{2} \mathrm{O}_{3}$ has been used in the treatment of acute promyelocytic leukemia (Waxman and Anderson, 2001) and has obtained the Food and Drug Administration (FDA) approval in September 2000. However, today main use of arsenic is as pesticides, veterinary drugs, herbicides and silvicides; smaller amounts are used in the glass and ceramics industries and as feed additives (Friberg et al., 1986). Drinking water is the principal source of arsenic exposure to human and animal, although occupational exposures occur, particularly in the metal smelting and glass making industries (Bode and Dong, 2002; Yih et al., 2002). Now a day, arsenic exposure through food chain has been reported (Naidu et al., 2006). The arsenic disaster of Bangladesh has been called the most terrible environmental catastrophe of the twentieth century. WHO described the condition as "the largest mass poisoning of a population in history" (WHO, 2004). It was estimated that 59 out of 64 districts and about $29 \%$ of the total tube wells in Bangladesh are contaminated with arsenic (Khan et al., 2006; Chakraborti et al., 2010) and about 85 million people are at risk of drinking arsenic contaminated water and foodstuffs (Wahidur, 2006).

*Corresponding e-mail address: a.wares.bau@gmail.com 


\section{A. Wares and others}

Chakraborti et al. (2010) showed that hand tube wells of the table land and hill tract regions of Bangladesh are primarily free from arsenic contamination, while the flood plain and deltaic region including the coastal region are highly contaminated with arsenic. The extent of this environmental disaster is greater than any other recorded in human history.

As Black Bengal goat is special for their kidding performance. Reproductive capacity may be affected by the arsenic. There is no established report on the effect of arsenic on reproductive organs of Black Bengal goat. In the Mymensingh district, Buror Char, Dhobaura, Fulpur and Haluaghat are the most arsenic affected areas (DPHE, 2009). Considering all those aforementioned observations, the present work has been undertaken on female Black Bengal goats to determine the gross and microscopic effects of arsenic on uterus. Ultimately, this result will help to draw the conclusion about the effects of arsenic on reproduction of female Black Bengal Goats.

\section{MATERIALS AND METHODS \\ Collection of samples}

A total of twelve mature female Black Bengal goats were used in this study. Six (two from Buror Char, two from Dhobaura, one from Fulpur and one from Haluaghat upa-zilla of Mymensingh) mature female Black Bengal goats were purchased for experiment being aware that the goats have been reared in those specific areas from their birth. Control group of goats (sx) were purchased from the arsenic free areas of Hill Tracts of Chittagong (Chakraborti et al. 2010). The goats were sacrificed by piercing carotid artery and uterus were collected immediately in the postgraduate laboratory, department of Anatomy and Histology, Bangladesh Agricultural University (BAU), Mymensingh.

\section{Gross and Histological Study}

Just after collection of female reproductive organ (uterus), the gross morphology (color and shape) and biometry (size and weight) were measured and recorded. For histological studies, the tissues were trimmed and then fixed in the "Bouin's fluid" (Gridley, 1960), dehydrated in the series of asecnding grades of alcohol, cleared in three changes in xylene, filtrated in three grades of melting paraffin in the oven of $58^{0} \mathrm{C}$ and embedded in paraffin of $58^{0} \mathrm{C}$ melting temperature. Then the sections were cut into $6 \mu$ thickness using rotatory microtome (MIC 509, Euromex, Japan). The sections were stained using Mayer's Hematoxylin and Eosin Formula (Luna, 1968).

\section{Photomicrograph and Statistical Analysis}

The stuctures were observed by light microscope using convenient magnification, measurement of important structures was taken by the calibrated stage micrometer and photomicrograph was taken for better illustration using photomicrographic camera (Olympus PMC 35 Model). The recorded data were compiled and tabulated for statistical analysis by the help of Computer package SPSS 11. The mean was compared using One-way ANOVA Method.

\section{RESULTS AND DISCUSSION}

\section{Gross effects of arsenic on horn of uterus}

The color of the horns of uterus was yellowish white. The length of the horns of uterus of aresenic affected goat and control group goat was $13.81 \pm 0.14 \mathrm{~cm}$ and $13.88 \pm 0.13 \mathrm{~cm}$ respectively. The width of the horns ofuterusof aresenic affected goat and control group goat was $1.45 \pm 0.04 \mathrm{~cm}$ and $1.43 \pm 0.04 \mathrm{~cm}$ respectively. The breadth of the horns of uterusof aresenic affected goat and control group goat was $3.47 \pm 0.04 \mathrm{~cm}$ and $3.53 \pm 0.06$ $\mathrm{cm}$ respectively. The weight of the horns ofuterus of aresenic affected goat and control group goat was $30.80 \pm 0.38 \mathrm{~g}$ and $31.64 \pm 0.31 \mathrm{~g}$ respectively. It was observed that the difference of length, width, breadth and weight of horns of uterus between arsenic affected group and control group was statistically insignificant (Figure1, 2).

\section{Gross effects of arsenic on body of uterus}

The color of the body of uterus was yellowish white. The length of the body of uterus of aresenic affected goat and control group goat was (mean \pm SE) $3.29 \pm 0.05 \mathrm{~cm}$ and $3.41 \pm 0.08 \mathrm{~cm}$ respectively. The width of the body of uterus of aresenic affected goat and control group goat was $1.62 \pm 0.03 \mathrm{~cm}$ and $1.69 \pm 0.04 \mathrm{~cm}$ respectively. The breadth of the body of uterus of aresenic affected goat and control group goat was $4.61 \pm 0.06 \mathrm{~cm}$ and $4.55 \pm 0.06$ $\mathrm{cm}$ respectively. The weight of the body of uterus of aresenic affected goat and control group goat was $4.63 \pm 0.07$ $\mathrm{g}$ and $4.76 \pm 0.05 \mathrm{~g}$ respectively. 


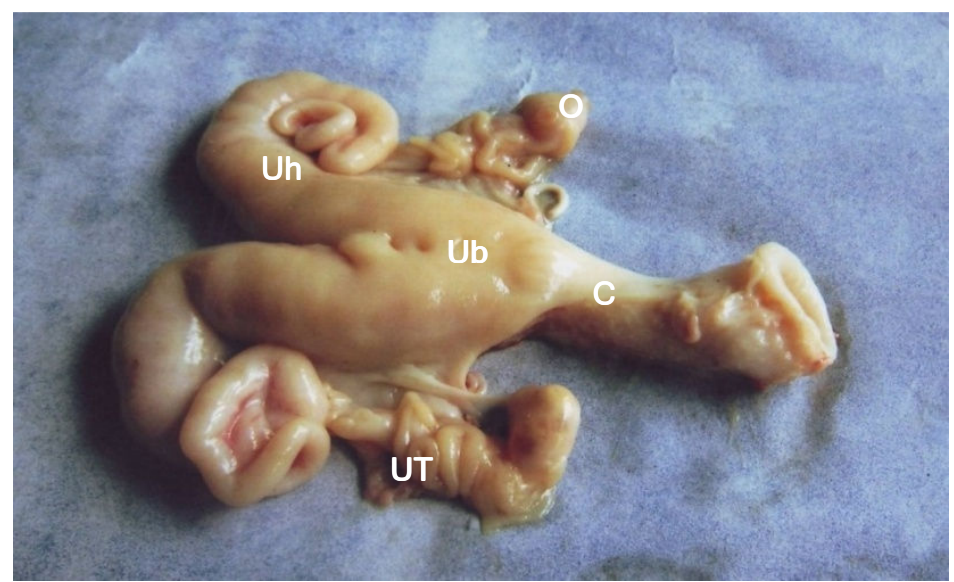

Figure 1. Gross effects of Arsenic on female genital system. Figure shows Ovary (O), Uterine tube (UT), Uterine horn (Uh), Uterine body (Ub) and cervix (C). There is no visible lesions of arsenic on uterus.

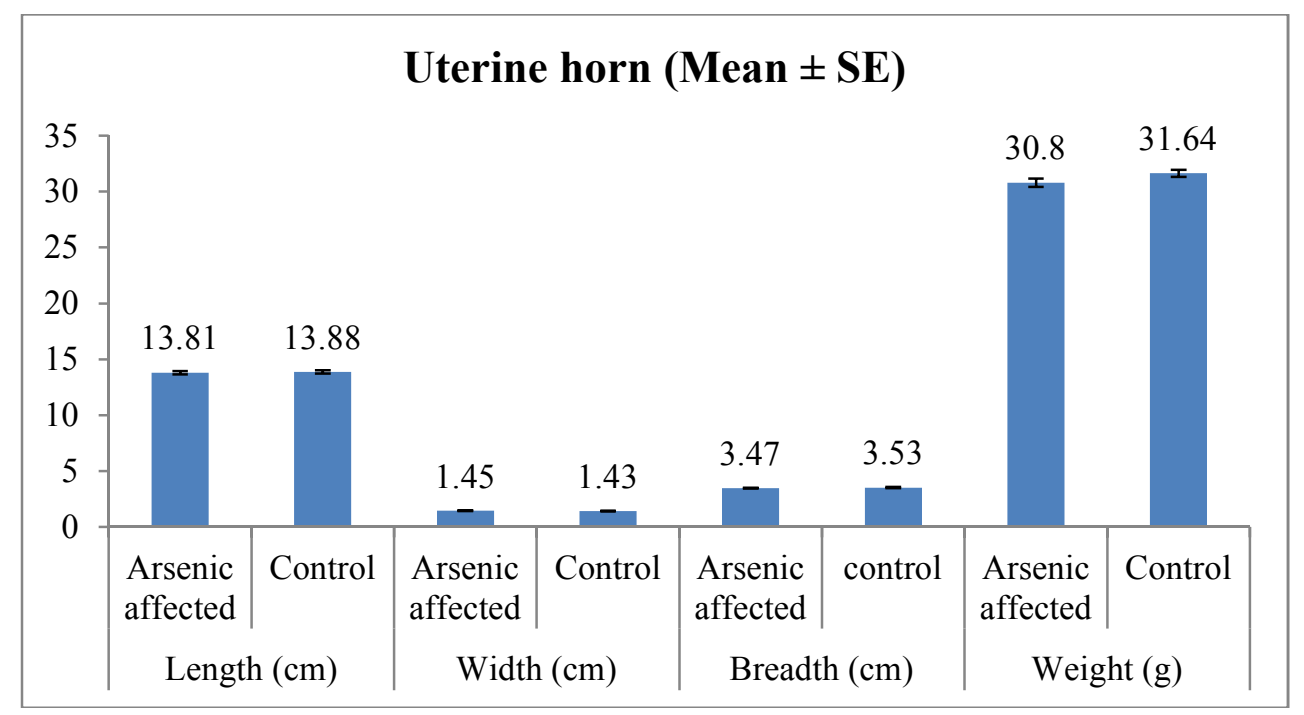

Figure 2. Comparison of mean of lenght, width, breadth and weight of uterine horn between arsenic affected and control group of goats through 2-D column chart $(\mathrm{N}=12)$, the variation is not significant $(p>0.05), \mathrm{SE}=\mathrm{Standard}$ error

The difference of length, width, breadth and weight of body of uterus between arsenic affected group and control group was statistically insignificant (Figure1, 3).

\section{Gross effects of arsenic on cervix}

The color of the cervix was pale white to yellowish white. The length of the cervix of aresenic affected goats and control group goat was (mean \pm SE) $3.48 \pm 0.05 \mathrm{~cm}$ and $3.46 \pm 0.06 \mathrm{~cm}$ respectively. The width of the cervix of aresenic affected goats and control group goats was $1.43 \pm 0.03 \mathrm{~cm}$ and $1.51 \pm 0.03 \mathrm{~cm}$ respectively. The breadth of the cervix of aresenic affected goat and control group goat was $5.44 \pm 0.04 \mathrm{~cm}$ and $5.43 \pm 0.06 \mathrm{~cm}$ respectively. The weight of the cervix of aresenic affected goat and control group goat was $6.87 \pm 0.09 \mathrm{~g}$ and $6.93 \pm 0.11 \mathrm{~g}$ respectively. The difference of length, width, breadth and weight of cervix of uterus between arsenic affected group and control group was statistically insignificant (Figure1, 4). 


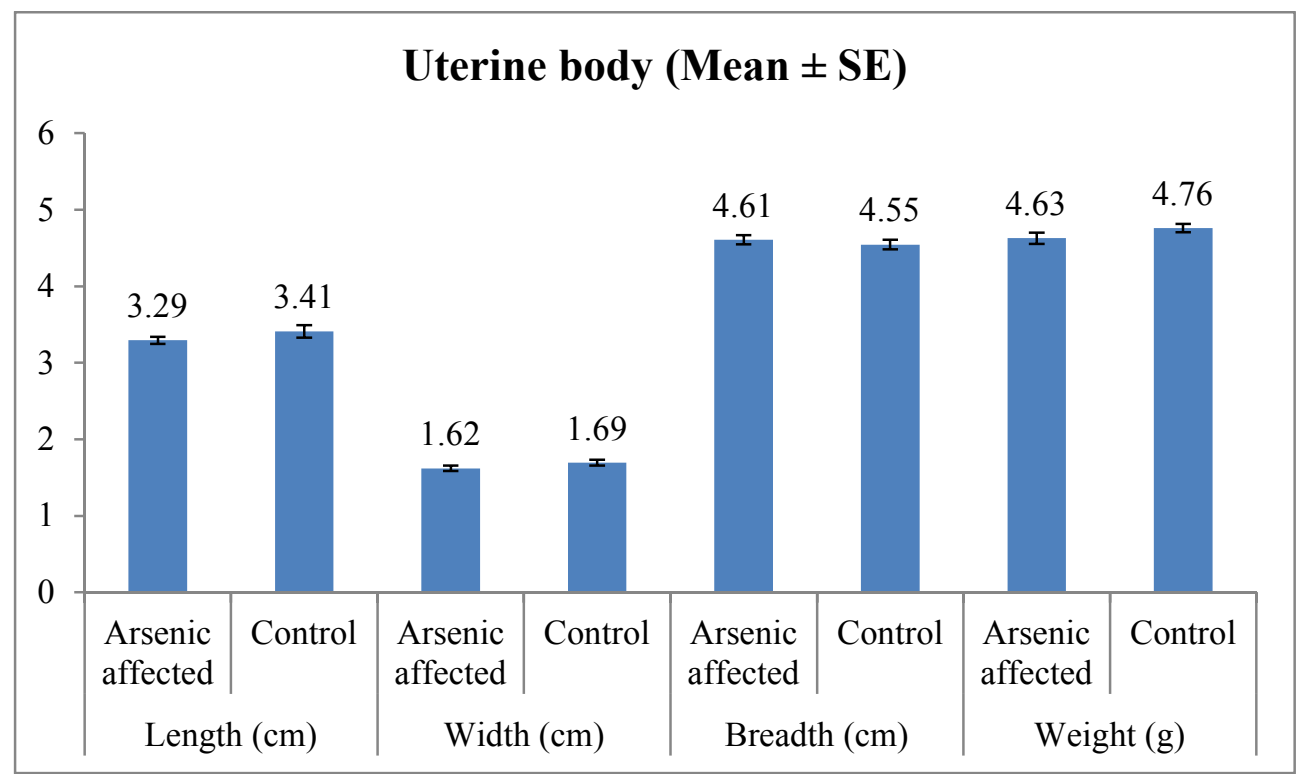

Figure 3. Comparison of mean of lenght, width, breadth and weight of uterine body between arsenic affected and control group of goats through 2-D column chart $(\mathrm{N}=6)$, the variation is not significant $(p>0.05), \mathrm{SE}=\mathrm{Standard}$ error

\section{Histological effects of arsenic on uterus}

The uterus, together with the cervix and the vagina, represents the fused caudal portion of the Mullerina ducts. The lamina epitheliallis mucosa is simple columnar, with patches of pseudostratified columnar epithelium in the pig and ruminants. Cyclic changes are observed in the mucosa and uterine surface epithelium, which are dependent upon the cyclic activity in the ovary. Our sample goat was dry period or non-pregnant animal. Lamina propria is close to the surface, the propria is very rich in cells. The lamina muscularis mucosae is absent. Submucosa is loose connective tissue, it contains fewer cells than the propria. Tunica muscularis is consists of a inner circular layer which isvery thick and a outer longitudinal layer which is not as prominant. The serosa contains an unusually large amount of longitudinally running smooth muscle fibers which often fuse with the myometrium.

Present study shown that uterine horns has thickened in arsenic affected group of goats. Measured thickness of uterine horn was (mean \pm SE) $1142.08 \pm 35.72 \mu \mathrm{m}$ and $954.00 \pm 24.17 \mu \mathrm{m}$ in arsenic affected goats and control group of goats. The difference between arsenic affected and control group is statistically significant $(p<0.01)$ (Figure 5, 6). Submucosa contains uterine gland but in smaller in amount and diameter. Measured diameter of uterine gland was $157.50 \pm 7.86 \mu \mathrm{m} 116.33 \pm 5.85 \mu \mathrm{m}$ in arsenic affected goats and control group of goats. The difference between arsenic affected and control group is statistically significant $(p<0.01)$ (Figure 5, 7). Cervical villi length was smaller in experimental group of animals. Measured length was $817.96 \pm 41.68 \mu \mathrm{m}$ $1130.08 \pm 47.05 \mu \mathrm{m}$ in arsenic affected goats and control group of goats. The difference between arsenic affected and control group is statistically significant $(p<0.01)$ (Figure 5, 9). Cervical wall thickness was higher in experimental group of animals. Measured thickness was $1479.17 \pm 98.44 \mu \mathrm{m} 1442.08 \pm 96.68 \mu \mathrm{m}$ in arsenic affected goats and control group of goats. The difference between arsenic affected and control group is statistically insignificant (Figure 5,8). This observation is more or less similar to the observation of SandipChattopadhayay et. al. (2003). They observed significant reduction in the plasma levels of leutinizing hormone (LH), follicle-stimulating hormone (FSH), and estradiol along with a significant decrease in ovarian activities of delta five, 3 beta-hydroxysteroid dehydrogenase, and 17 beta-hydroxysteroid dehydrogenase followed by a reduction in uterine peroxidase activities due to the effect of aresenic.A significant weight loss of the uterus was also observed after this arsenic treatment, along with a prolonged diestrous phase and a high accumulation of arsenic in the plasma and these organs. Moreover, sodium arsenite was also responsible uterine cell degeneration characterized by reduction in the uterine luminal diameter, in comparison with the controls. Akram et. al. (2009) observed loosening of cells in myometrium of uterus, proliferation of connective tissue and shortened cervical villi. 
Islam et. al. (2005) observed decreased fertility due to arsenic toxicity. Zhang et. al. (2003) observed the pregnancy rate, normal parturition and feeding in the high dose (arsenic) group were lower than those in the low dose and control groups. Islam et al. (2011) showed that lower number of glands in endometrium and smaller cervical crypts. The basic difference with the research of Islam et. al. (2011) is, the present research was done in naturally intoxicated animal where that was done with artificial intoxication. Little effects of As, and insignificant differences among control and arsenic affected goats, on the gross parameters may be due, in part, to the rapid elimination of As, and for the ample supply of green grass. To draw accurate predictions of outcomes, analyses of large number of samples with wide ranges of contamination are needed. However, the result will certainly help to provide guidance in carrying out further studies.

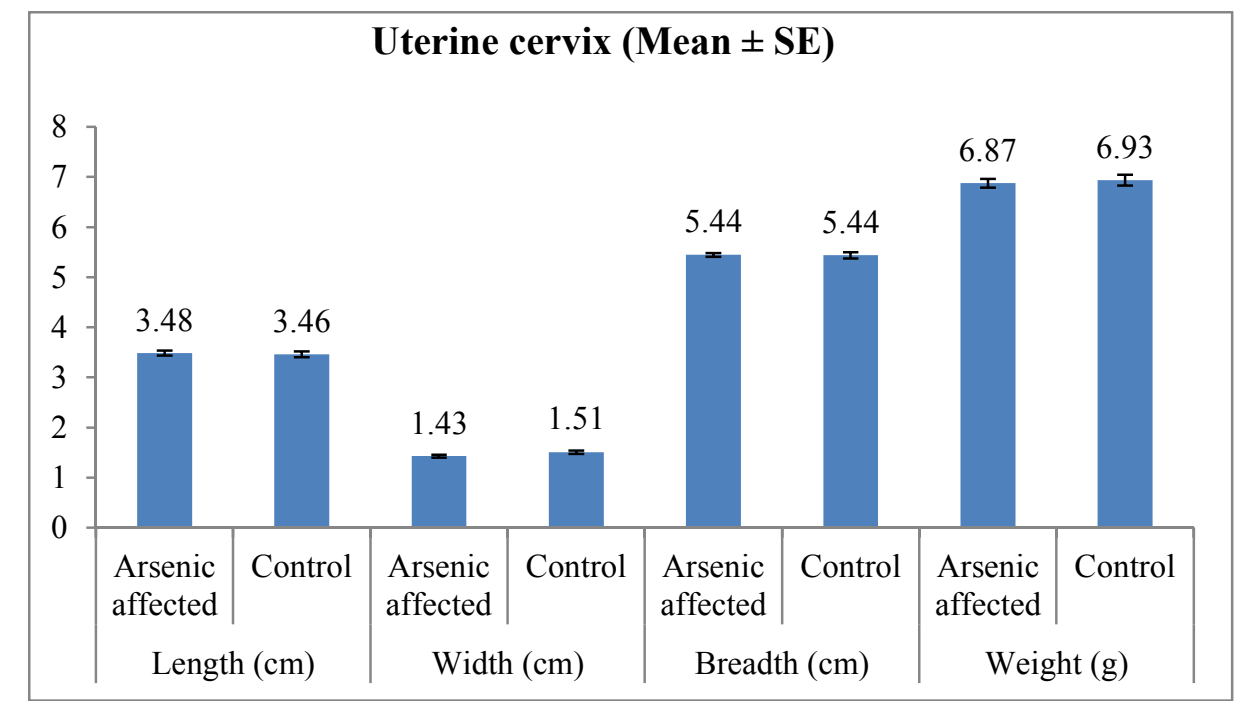

Figure 4. Comparison of mean of lenght, width, breadth and weight of uterine cervix between arsenic affected and control group of goats through 2-D column chart $(\mathrm{N}=6)$, the variation is not significant $(p>0.05)$, $\mathrm{SE}=\mathrm{Standard}$ error

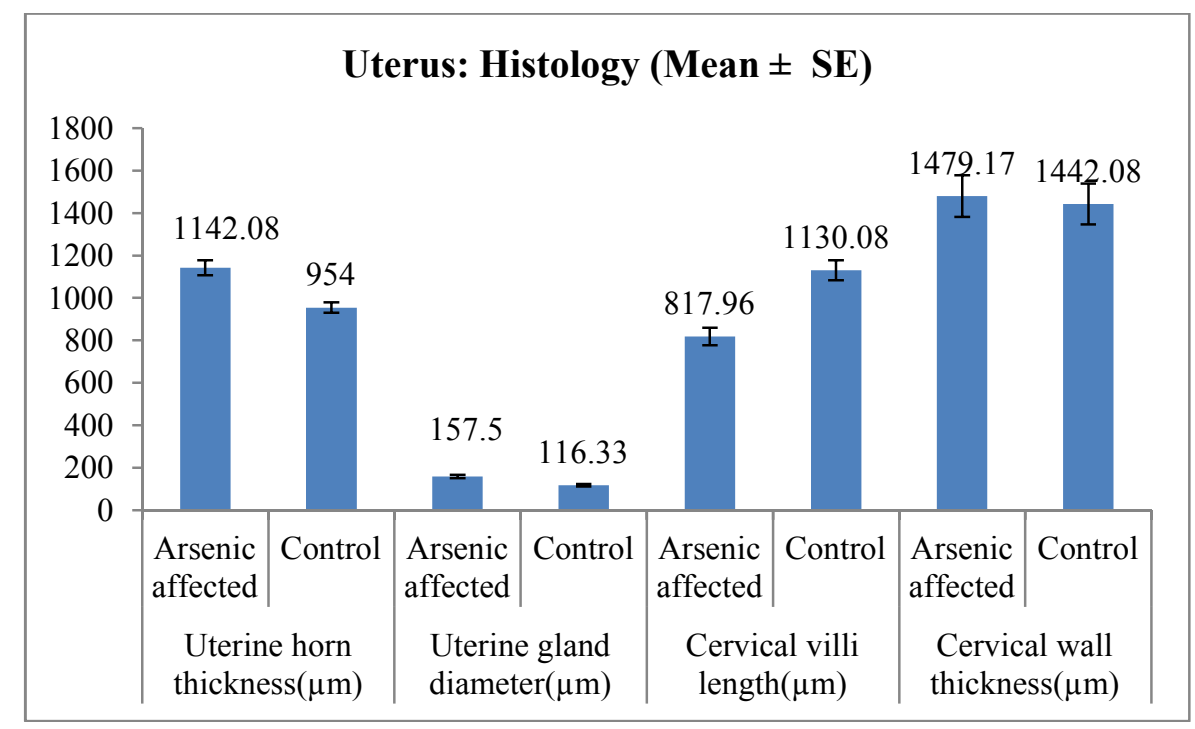

Figure 5. The comparison of mean of thickness wall of uterine horn $(\mu \mathrm{m})$, diameter of uterine gland $(\mu \mathrm{m})$, length of cervical villi $(\mu \mathrm{m})$ and cervical wall thickness $(\mu \mathrm{m})$ between arsenic affected and control group of goats through 2-D column chart $(\mathrm{N}=12)$, the variationis significant $(p<0.05$ and $p<0.01)$ 


\section{A. Wares and others}
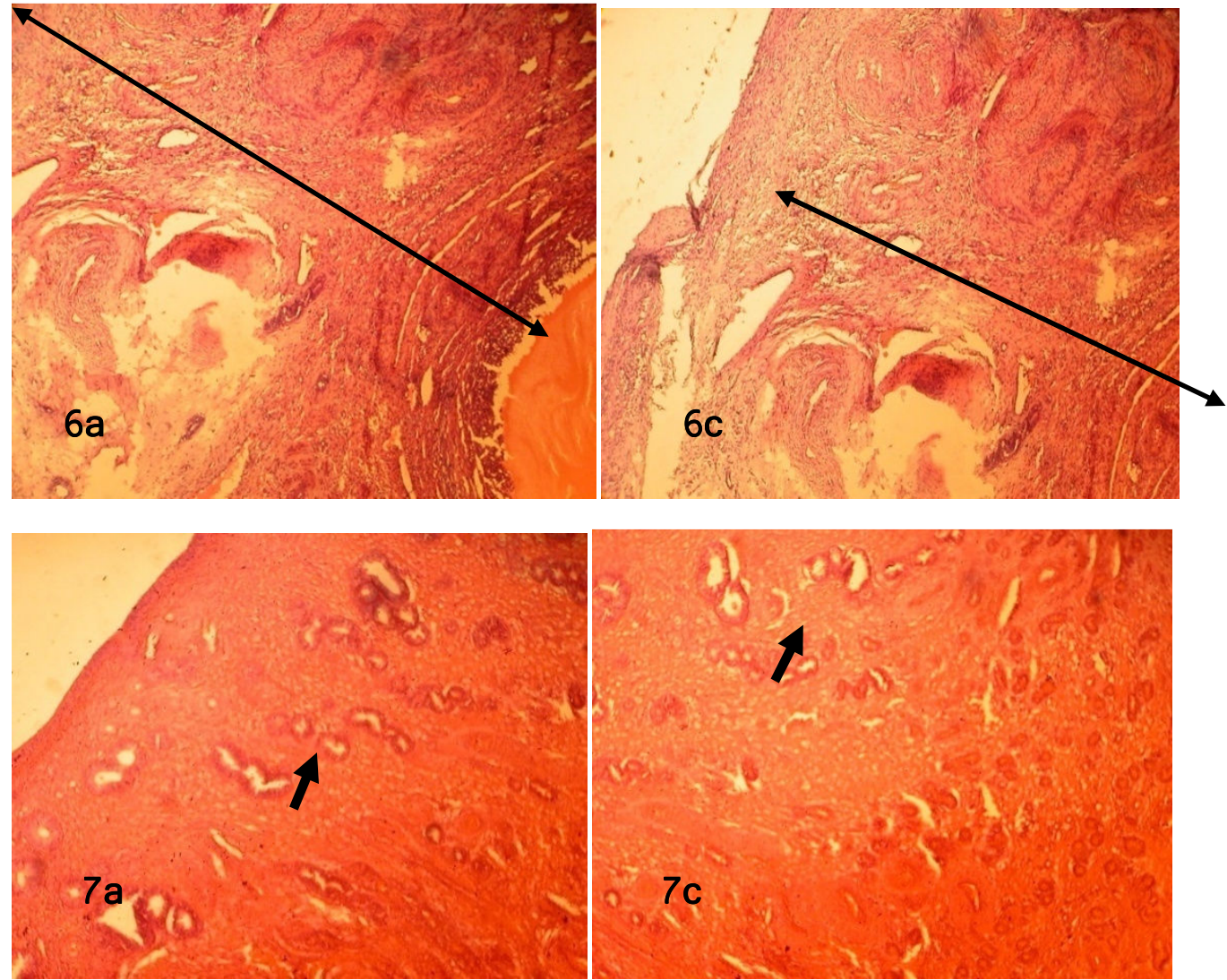

Figure 6, 7. Histological effects of arsenic on uterine horn and body. Figure shows thickening of uterine horn wall in arsenic affected goats (6a) compare to that of control group (6c). The uterine gland is fewer in number and smaller in diameter in arsenic affected goats (7a) compare to that of control group (7c), (H \& E stain 20x)
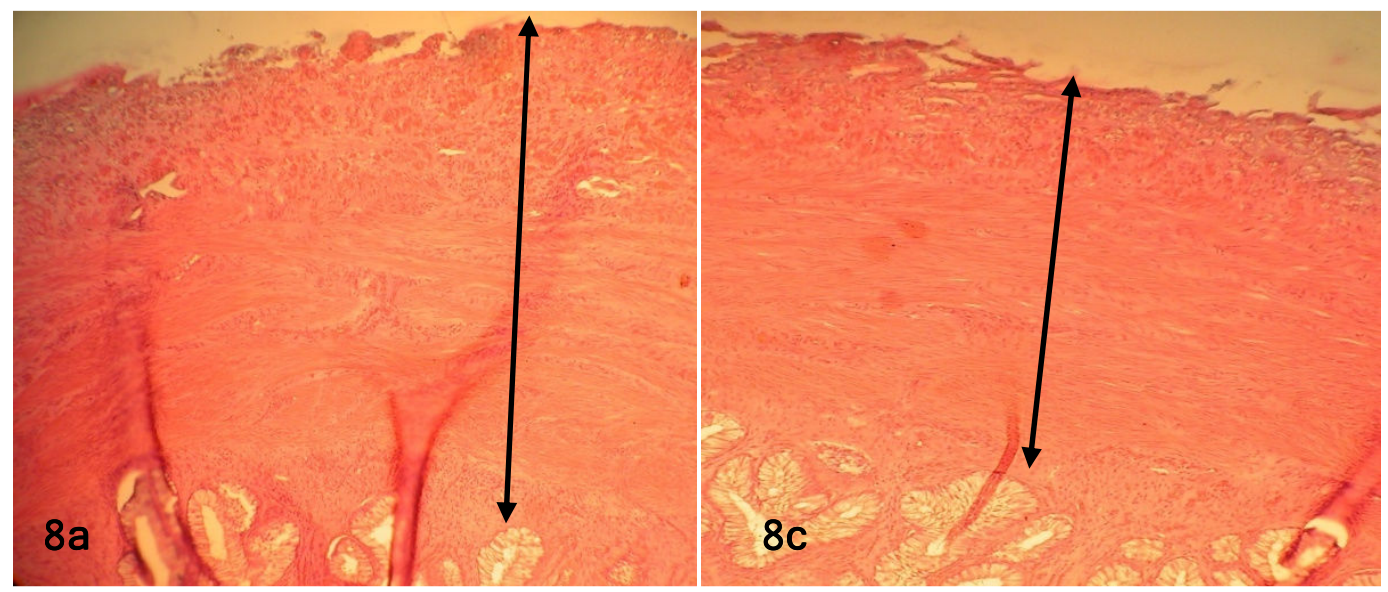

Figure 8. Figure shows thickening of uterine cervical wall in arsenic affected goats (8a) compare to that of control group of goats (8c) (H \& E stain 20x) 

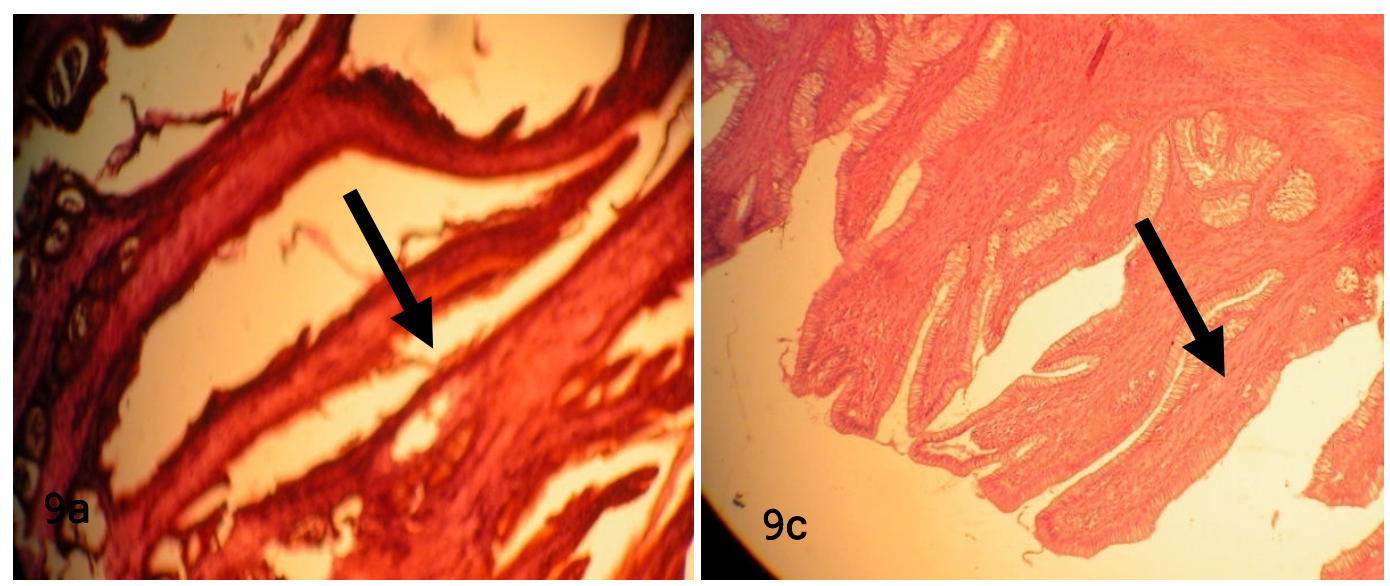

Figure 9. Cervical villi length is smaller in arsenic affeted goats (9a) compare to that of control group of goats (9c) (H \& E stain 40x)

\section{ACKNOWLEDGEMENT}

This research was funded by Bangladesh Agricultural University Research System (BAURES).

\section{REFERENCES}

1. Akram Z, Jalali S, Shami SA, Ahmad L, Batool S and Kalsoom O (2009). Genotoxicity of sodium arsenite and DNA fragmentation in ovarian cells of rat. Toxicology Letters 190(1): 81-85.

2. ATSDR (Agency for Toxic Substances and Disease Registry) (2005). Toxicological Profile for Arsenic (Draft for Public Comment). Department of Health and Human Services, Public Health Service. Atlanta, GA: U.S. Available at: http://www.atsdr.cdc.gov/toxprofiles/phs2.html

3. Bode AM and Dong Z (2002). The paradox of arsenic: molecular mechanisms of cell transformation and chemotherapeutic effects. Critical reviews in oncology/hematology 42: 5-24.

4. Chakraborti D, Rahman MM, Das B, Murrill M, Dey S, Mukherjee SC, Dhar RK, Biswas BK, Chowdhury UK, Roy S, Sorif S, Selim M, Rahman M and Quamruzzaman Q (2010). Status of groundwater arsenic contamination in Bangladesh: A 14-year study report. Water Research 44(19): 5789-5802.

5. DPHE (Department of Public Health Engineering) (2009). Handbook on arsenic pollution in Mymensingh district of Bangladesh pp. 17-29.

6. FAO (1997). FAO Production Year Book. FAO of the United Nations, Rome Italy, Vol. 51: pp. 108-111.

7. Friberg L, Nordberg GF and Vook VB (1986). Handbook on the Toxicology of Metals, 2nd ed, Elsevier Science Publisher, Amsterdam, New York, Vol. II, pp. 43-83.

8. Goering PL, Aposhian HV, Mass MJ, Cebrian M, Beck BD and Waalkes MP (1999). The enigma of arsenic carcinogenesis: Role of metabolism. Toxicological Sciences 49: 5-14.

9. Gridley MF (1960). Manual of Histologic and Special Staining Technique. McGraw Hill Book Company, New York, NY, pp: 28-29 and 82-82.

10. Islam MA, Zaman MW, Shamsuddoha ATM, Haque FMA and Molla MOG (2005). Effect of long term groundwater irrigation on fertility status of surface soils in Nijhuri series under high barind tact. International Journal Sustainable Agricultural Technology 1(6): 49-54.

11. Islam MT, Parvin S, Pervin M, Bari ASM and Khan MAHNA (2011). Effects of chronic arsenic toxicity on the hematology and histoarchitecture of reproductive system of Black Bengal Goat. Bangladesh Journal of Veterinary Medicine 9(1): 59-66.

12. Khan MMH, Aklimunnessa K, Kabir M and Mori M (2006). Case-control study of arsenicosis in some arsenic contaminated villages of Bangladesh. Sapporo Medical Journal 75: 51-61.

13. Luna LG (1968). Manual of Histologic Staining Methods of the Armed Forces Institute of Pathology. 3rd edn. McGraw Hill Book Co. New York, USA.

14. Morand-Fehr and Boyazoghu (1999). Animal Distribution Records 30: 2540.

15. Naidu R, Smith E, Owens G, Akter K, Khan NI, Huq I and Rahman M (2006). Potential arsenic exposure pathways in Bangladesh. Paper Presented at 6th International Conference on "Safe Water and Safe Food Options in Arsenic Mitigation: Lesson Learnt", held at $4-5$ January, 2006, Dhaka, Bangladesh. 
16. Chattopadhayay S, Pal S, Ghosh D and Debnath J (2003). Effcets of dietary co-administration of sodium selenite on sodium arsenite-induced ovarian and uterine disorders in mature albino rats. Toxicological Sciences 75(2): 412-422.

17. Wahidur R (2006). Arsenic Exposure in Bangladesh: The Reproductive and Developmental Health Effects in Humans. Philadelphia Annual Meeting held on 22-25 October, 2006. Paper No. 67-3.

18. Waxman S and Anderson KC (2001). History of the development of arsenic derivatives in cancer therapy. The Oncologist 6: 3-10.

19. WHO (World Health Organization) (2004). Water Sanitation and Health. World Health Organization. Geneva.

20. Yih L, Peck K and Lee T (2002). Changes in gene expression profiles of human fibroblasts in response to sodium arsenite treatment. Carcinogenesis 23: 867-876.

21. Zeuner FE (1963). History of domestic animals. Hutchinson and Co. Ltd., London, UK, pp. 2641.

22. Zhang C, Ling B, Liu J and Wang G (2003). Toxic effect of fluride-arsenic on the reproduction and development of rats. Fluoride 36(2): 13. 